\title{
Digitalism: The New Realism?
}

\author{
Jonathan P. Bowen \\ Birmingham City University \\ School of Computing, Telecomms \& Networking, \\ Birmingham, United Kingdom \\ http://www.jpbowen.com \\ jonathan.bowen@bcu.ac.uk
}

\author{
Tula Giannini \\ Pratt Institute \\ School of Information \& Library Science, \\ New York, United States \\ http://mysite.pratt.edu/ giannini/ \\ giannini@pratt.edu
}

\begin{abstract}
Today's society is increasingly digitalised, with mobile smartphones being routinely carried and used by a significant percentage of the population. This provides an augmented experience for the individual that does not depend on their geographical separation with respect to their community of friends and other contacts. This changes the nature of relationships between people. Individuals may live in a "digital bubble", close to others physically, but far away from them in their digital world. More specifically, digital images can be generated and shared with ever greater ease. Sometimes the digital image takes on an important part of the individual's experience of reality. This paper explores examples of the phenomenon, within the context of the arts in particular and culture in general. We also consider the assortment of terms used in a variety of ways by researchers in different fields with regard to our ever more digital society, such as digitalism, digitality, digitalisation, digital culture, digital philosophy, etc. We survey these terms, exploring them from alternative viewpoints, including sociological and philosophical aspects, and attempt to pinpoint some of these terms more precisely, especially in a cultural and artistic context.
\end{abstract}

Digitalism. Digitality. Digitalisation. Digital culture. Digital philosophy. Realism.

\section{BACKGROUND}

"A room without books is like a body without a soul." - Cicero (106 BC - 43 BC)

It is as well to remember that fundamentally we are all programmed digitally. DNA provides a very large but finite number with a digital value that defines many of our characteristics (Figure 1:). That said, humankind have largely lived in an essentially analogue world for most of its development. Only in recent times with advances in computers and electronic communication have digital aspects really become important, on a par with our otherwise analogue experiences.

Of course the mathematical basis for digital technology has existed for many centuries. The first digital technology was mechanical, with devices such as the abacus and subsequently more complicated calculating machines. Digital communication has included semaphore, Morse code, etc. Gradually the technology has moved from mechanical to electrical foundations. In the $19^{\text {th }}$ century, the "Victorian Internet" was born in the form of the telegraph (Standage 1999), In the $20^{\text {th }}$ century, electronics allowed miniaturisation and vast increases in processing and communication speed and similarly impressive reductions in cost, together with improved theoretical understanding (Bowen 2012). The use of technology for art gradually followed. This was delayed by the high cost of digital technology initially, but as this dropped dramatically, its use for artistic purposes became increasingly possible (Brown et al. 2008).

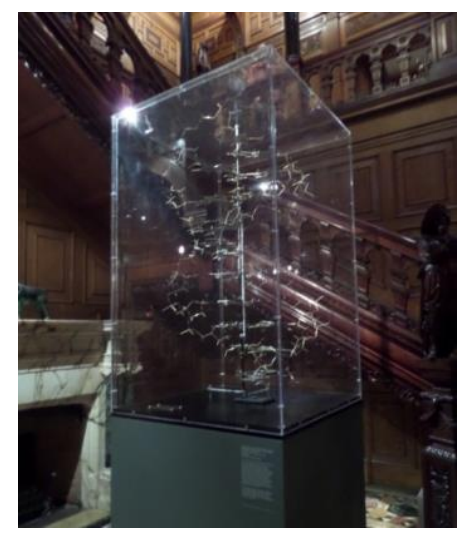

Figure 1: Model of DNA originally by Crick and Watson, on display at Two Temple Place, London

(University of Cambridge Museums 2014)

The microprocessor revolution started in the 1970 s (Evans 1979) allowed computation to be accessible in the home using the personal computer during the 1980s. The advent of the Internet enabled global digital communication initially for the cognoscenti and latterly with the advent of the simple-to-use World Wide Web from the 1990s, for large numbers of the general worldwide population (Berners-Lee 1999) 
In the 2000s, Web 2.0 allowed increasingly more social interaction - e.g., through blogs (Beazley 2010) - with vast new digital companies such as Facebook, Twitter, etc., expanding rapidly. Crowdsourcing, crowd-funding, etc., became feasible, even in the context of arts and museums (Black et al. 2010). Now in the 2010s we are in a state where digital technology is ubiquitous in advanced modern society with mobile devices enabling access to the Internet from anywhere (FilippiniFantoni \& Bowen 2008). Even in poorer cultures, the cost is at a level where the use of digital devices such as mobile and now smart phones is increasingly possible.

\section{INTRODUCTION}

Negroponte (1995) introduced the concept of Being Digital in his foresightful book. He compared the need for transporting atoms (material goods, but also conveyors of information such as paper) with the much cheaper and faster use of electrons for communication. McLuhan (1962, 1992) also foresaw many of the media changes that we have seen over recent decades, especially with respect to increasingly close electronic connectivity.

Now the digitalisation of people is nearly ubiquitous in advanced societies where almost everyone who desires a smartphone can afford to have one. The window that this provides to the individual wherever that are is an alternative form of communication and interaction with the world that no longer depends on geographical proximity or location. What is more, users wish to record their real-life experiences and share them with their digitally connected friends and others. This phenomenon is especially prevalent in the context of the arts where users are experiencing a potentially meaningful and to them uniquely personalised experience that they wish to communicate with others not co-located with them or save for possible later use.

An extreme example is The Mona Lisa in the Louvre, Paris. Here, a sea of people are kept are some distance from the object itself by the museum authorities, for security and perhaps safety reasons. The picture becomes an altar to those present. The view of the object itself is far worse that could be obtained online, for example, through the Art Project of the Google Cultural Institute (http://www.google.com/culturalinstitute). Yet the viewers are in the presence of the real object itself and wish to record this experience. Thus a sea of smartphones, tablet devices, and some digital cameras are held aloft by the crowd to capture what in most cases with be a rather indistinct digital image of the physical picture (Figure 2: and Figure 4:). This may be broadcast to friends on social media, viewed later to remember the experience, or quite possibly never seen again by a human eye.

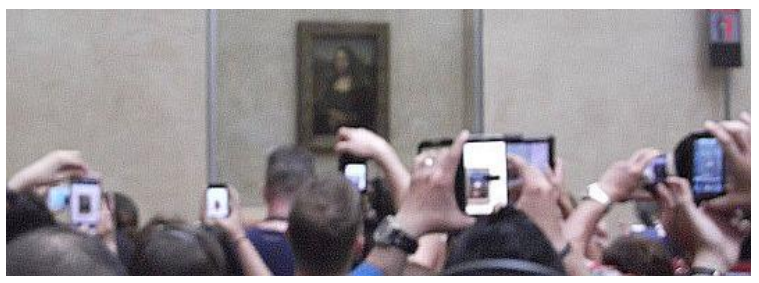

Figure 2: Viewing the Mona Lisa (Louvre, Paris)

Even more extremely, during EVA London 2013 at the stage door of one of the London theatres, a crowd surrounded the stage door in anticipation, again with a sea of arms, digital devices, and indistinct images of the door area recorded for posterity. Yet in this case, the object of veneration was not even there. Daniel Radcliffe, of Harry Potter fame, was due to be leaving after a West End performance, but had not yet actually appeared. All that was being recorded was an empty doorway (Figure 3:).

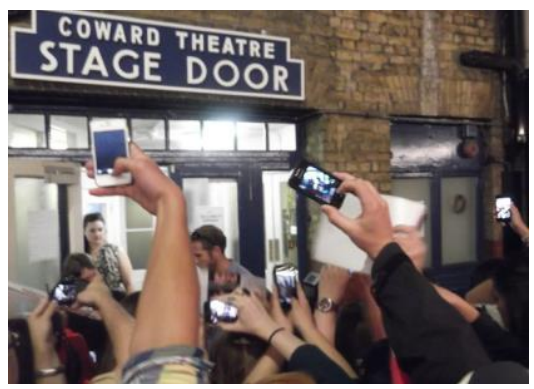

Figure 3: Digitally viewing an actor that is not there

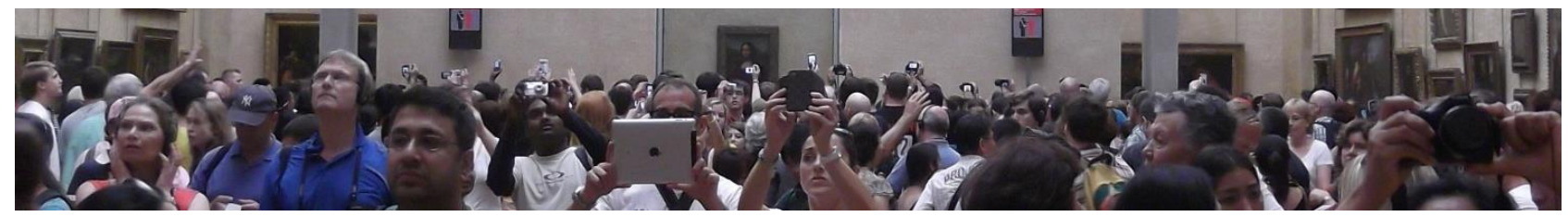

Figure 4: A sea of digitalism at the Louvre, Paris

\section{DEFINITION OF DIGITALISM}

The term "digital" derives from the Latin for finger, digitus (Quinion 2002). It has been adopted to refer to discrete mathematical numbers, whether they are base 10 digits due to the number of fingers on a pair of human hands or, in more recent times, base 2 binary digits in a digital computer. The related term "digitalism" is somewhat confusingly used in a number of different ways, depending on the field. In medicine, digitalism refers to a medical condition, related to poisoning by digitalis, the stimulant drug extracted from foxglove plants (http://dictionary.reference.com/browse/digitalism, Ishimaru \& Yokogawa 2006). 
For mathematicians and theoretical physicists, digitalism can refer to "digital philosophy" (Wikipedia 2014), in which the universe can be seen as a very large computational device (Wolfram 2002). In fields related to the study of Information Technology, the term is used in a more sociological sense with respect to the adoption of digital devices by people in a ubiquitous manner, where the presence of computer and communication devices becomes so prevalent that users forget the fact that these devices are computer-based, whether they are mobile (e.g., smartphones) or embedded in the home (e.g., smart televisions). In the arts, the term has been used to refer to the increased use of computers for digital art (Daudier 2001) and digital music (Muenz 2010), for example.

In summary, the term "digitalism" has different meanings in different contexts. In this paper, we take it to refer to the phenomenon of the "digitalisation" of society, i.e., the near ubiquitous uptake of digital devices, most notably smartphones at present, that are taken as a matter of course by the majority of people, especially those young enough not to have experienced a non-digital society. Of course, the exact nature of the future is unknown, but it will certain have increasingly digital aspects with new miniaturised devices embedded in our everyday possessions, such as eye glasses (e.g., Google Glass, http://www.google.com/glass/), clothes, and even works of art.

Further related terms such as "digitality" (cf. "reality"), referring to the condition of living in a digital culture, have also been coined (Negroponte 1995). However, all such neologisms are in a state of flux as digitalism develops rapidly and unpredictably.

\section{DIGITAL DESTRUCTION}

Digitisation of information is a disruptive innovation. For example, the book is in danger of disappearing in paper form, especially where it is purely for information rather than decorative purposes (e.g., see Figure 5:). The major reference work Encyclopædia Britannica ceased being printed in 2012 and with the onslaught of the freely available, more extensive and rapidly updated competitor Wikipedia, has a difficult struggle to survive. In 1996, the date predicted for the book becoming digital by Wired was 2013 (Wieners \& Pescovitz 1996), We are certainly on the road to this prediction with the use of Kindles and no doubt further improved paper-like technology such as "electronic paper" in the future.

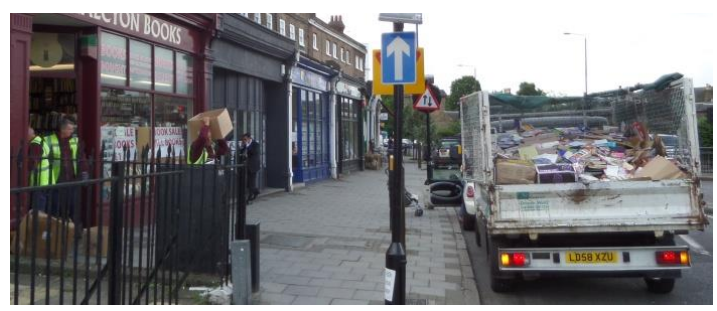

Figure 5: Bookshop clearance (Greenwich, London)

Libraries, including major archival institutions like the US Library of Congress, have in the past destroyed printed material after transferring it to another medium such as microfiche (Baker 2002). The BBC similarly reused video tapes, destroying classic television material in the process due to the expense of early video tape, without saving it systematically onto any other electronic medium (http://www.bbc.co.uk/archive/tv archive.shtml?cha pter=6). However in this latter case, the possibility of cheap digital recording can help to save the original fragile material in electronic archives.

The role of modern libraries is changing radically in response to digitalisation. Whereas libraries used mainly to lend or allow access to physical books, now find that their books are becoming increasingly like wallpaper. Instead, library spaces are used for Internet access and social reasons (see Figure 6:). Libraries must adapt significantly in order to survive the digital future.

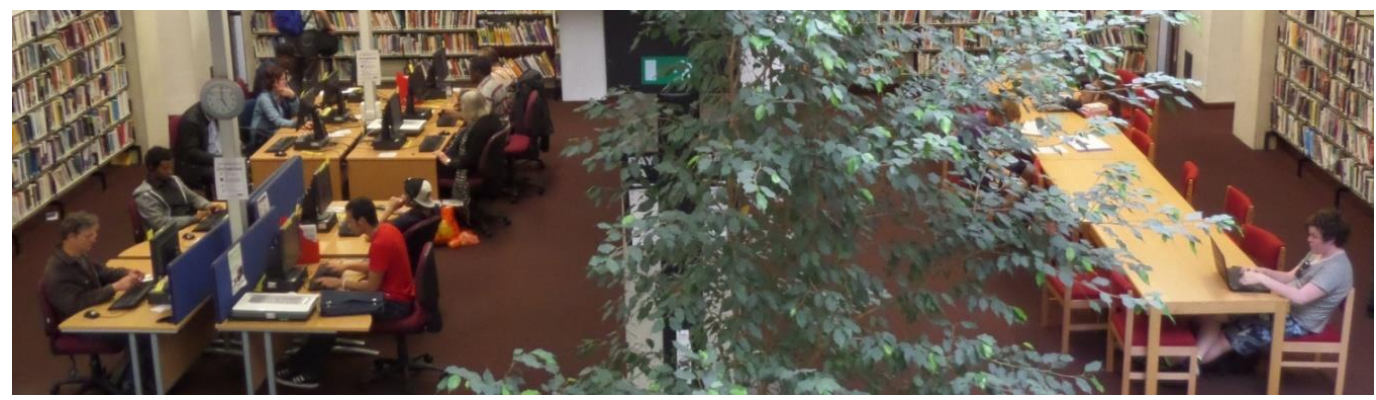

Figure 6: Digital technology extensively used on the left; table space for reading analogue books almost empty apart from a laptop user on the right (Oxford Central Library)

\section{DIGITAL CREATIVITY}

"As the unity of the modern world becomes increasingly a technological rather than a social affair, the techniques of the arts provide the most valuable means of insight into the real direction of our own collective purposes."

- Marshall McLuhan (1911-1980)

Despite the disruptive and potentially destructive nature of digitalism, it can also enable huge new 
opportunities for creativity. The history of human progress with respect to developing knowledge has depended on creativity and invention through the centuries (van Doren 1991). Approaches have varied depending on the cultural environment. For example, linear thinking is favoured in Western cultures and a more holistic view has been prevalent historically in Eastern cultures (Alcorn 1997). The necessary creativeness associated with science and art is a matter for debate, with scientific advances often being termed as discoveries rather than creations (Robinson 2010). Despite this, a creative nature is needed for significant advances in all disciplines. For course, different personalities can affect the way that the creative process is approached (Weisberg 2006), but this variety is itself probably an important aspect of creativity. Sometimes a combination of different creative minds can be beneficial in achieving a significant advance.

Visualisation has been an important part of scientific progress, especially since the advent of photography. Often these visual techniques reveal beyond what can be detected with the human eye alone (Darius 1984). With the availability of computers, it is possible to visualise in an even more abstract and complex way. For example, Stephen Wolfram explored the visualisation of cellular automata in his book $A$ New Kind of Science (Wolfram 2002). He also led the development of the Mathematica tool that allows mathematics to be captured and manipulated on a computer, providing visualisation facilities as well. Generation of these mathematical forms as graphical output can produce beautiful and artistic results (Bakshee 1999, Trott 1999).

Computers have enabled digital art to be created (Wiedemann 2001). Initially computers were too expensive to be used for artistic purposes by all but a few pioneers with privileged access (Brown et al. 2008), but this has changed radically as costs have dropped dramatically. Now, computers together with the Internet have become ubiquitous and relatively cheap to use by any artist that wishes to do so (Greene 2004). Mainstream artists such as David Hockney have embraced digital technology to produce completely digitally generated artworks, e.g., using the iPad (Gayford 2011), as exhibited at the Royal Academy (London) in his 2012 exhibition "A Bigger Picture". Grayson Perry has gone even further and has featured digital aspects of life, for example as a series of digitally woven tapestries presenting a story of the rise and fall of a computer scientist in a manner reminiscent of the $18^{\text {th }}$ century artist William Hogarth (Perry 2013).

Creativity can be seen as a process. Sometimes the process is as important as the result and can be interdisciplinary, involving both arts and science (Bowen \& d'Inverno 2006). With the almost ubiquitous availability of computing devices nowadays, creativity and computing often become intermixed. Creative computing may be said to be the use of computation in a novel, elegant, and perhaps artistic way, whereas computational creativity may be seen as using computers to achieve a creative result (Hugill \& Yang 2013). The former is more about the process whereas the latter is more concerned with the result. Both are important and worthwhile; indeed, they may ideally be achieved together. For example, in the case of David Hockey, his process of using an iPad to produce art is of interest as well as the result of that process, the electronic artwork itself. Sometimes it is possible to take this a step further and involve the end-user in the process as part of an interactive artwork, e.g., enabling remote communication via the Internet (Edmonds \& Franco 2013).

Electronic visualisation is an important part of digitalism and is now an accepted part of the arts and culture in general (Bowen et al. 2013). The visualisation may be an aid to gaining an understanding of cognitive, emotional, social, ethical, or political aspects of an issue (Sula 2013). This can potentially extend across any field of arts, humanities, or science, limited only by human creativity (Harrison et al. 2013). In particular, for example, online communities and the relationships between participants can now be visualised quite easily in an automated manner (Bowen 2013).

\section{EXPLORING DIGITALISM}

\section{1 (All things $) \times($ Digital $)=$ Digitalism}

From the digitisation of documents to the digitalisation of life itself and the birth of the digital self, digitalism demands new ways of doing, knowing, being, and thinking.

Digitalism has become a central driver of human activity and sits at the heart of all disciplines from medicine and science to the arts. What most distinguishes digitalism is that is goes beyond people using digital technology and tools to a new realm of digital behaviours so that people might spend more time being digital via their computers, smartphones, and tablets, compared to other life activities - whether in school, at home, at work, or on holiday - the digital aspect is present and part of one's daily interactions.

The Pew Research Project recently published the finding of two studies, one celebrating the first 25 years of the World Wide Web looking at the present and past (Fox \& Raine 2014), and another looking ahead to "Digital Life in 2025" (Anderson \& Rainie 2014). Considering the past, present, and future, the Pew statistics show a relentless growth in the numbers of Internet users, together with the rapid development and advance in digital technologies that drive society's digital future.

Hoy (2010) examines the extent to which the work of several modernist painters, including Paul Cézanne, Georges Seurat (Figure 7:), and Paul Klee, exhibits constitutive features of digital systems. Hoy (2010) notes: "I use my findings to argue that understanding these artists' roles as experimenters with a digital method adds a new dimension to the theoretical, aesthetic, and historical significance of their work," and she elaborates on how Seurat through pointillism and 
Paul Klee with pictorial notations are "modeling digitality." Significantly, digital photographers are using applications to create digital pointillism that well expresses seeing digitally and the digital self.

The Digital Self (T. Giannini, 2014)

There is a screen at the end of my mind

Easy to find

I see my face

I know where I am

My friends know too

On the street

Alone

Real places

Unknown faces

Leave no traces

Going home

Just me and my phone

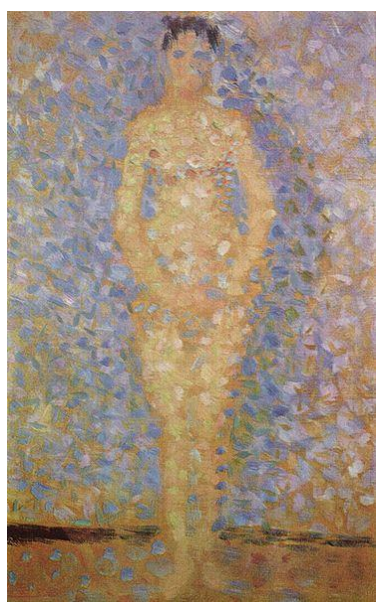

Figure 7: George Seurat, "Model Standing." Pointillism as a precursor of digital art and the digital self?

(Wikimedia Commons)

\subsection{Six degrees of digital separation to total digital integration}

As the digital self becomes a real actor of human existence, the separation that is perceived between digital things and real beings becomes increasing imperceptible, since the real self is transformed by the digital aspects.

\subsection{Digitalism and information - blurring the lines between human and digital}

Schools of information that follow the iSchool movement note on their website that iSchools, "share a fundamental interest in the relationships between information, people, and technology" (http://ischools.org/about/). In a similar sense, Human Computer Interaction $(\mathrm{HCl})$ studies delineate the "betweeness" of things (computers, technology) and people. While $\mathrm{HCl}$ is about how humans interact with technology, digitalism is more about people to people digital interactions and how we see and know ourselves and each other, where digital technology is the platform for human communication, creativity, and innovation. Thus, $\mathrm{HCl}$ conceptually represents more an old school framework, whereas digitalism frames human activity and is the lens through which we see the world and ourselves.

Digital art, influenced by digitalism, has moved from using digital tools to make an artwork as a framed image, to digital art that is digital in nature, networked, interactive, 3D, and often dynamic, changing in response to participant interactions as it can communicate and react to the "user."

\subsection{Digitalism - that which can be digital will be digital - a digital force field}

Digitalism is an inevitable progression from real to digital. It drives change, innovation, and creativity. It is increasingly a force that is unstoppable, irresistible, progressing toward everything digital so, that which can be digital is - that which is digital rules and replaces the old - that which is digital is sexy, desirable, and fascinating. As soon as a human activity goes digital, it gains momentum creating digital energy. The digital self is inescapable and means a self that is networked, global, personal and professional, real and imagined.

Digitalism has changed the relationship of users to information from one of seeking and receiving information to users as content creators and full participants in publication and communication of information via the Internet and web.

This shift away from users being information receivers to being full participants in the information process has dramatic impacts and establishes new roles for individual expression, empowered by digital tools and technology (Giannini 1999a). There is more user-generated content on the web than publishers' content. For example, Wikipedia and other similar content platforms are becoming dominant and gaining authority. A new digital divide between what is known and what is unknown is the difference between the digital online world and physical offline resources. Digital is almost always online, as digital information and objects are created to be shared and communicated.

Information and knowledge creation are now implicit between institutions and individuals so, for example, libraries, archives, and museums, publish their collections and shape that communication of content through web design, narrative, metadata, and description. Communities of practice can create, gather and share information and through platforms such as Twitter and wikis, generating community discussion and interaction (Liu \& Bowen 2011).

The lines between physical and digital experience and interactions are blurred (Lawrence \& Stump 2012). But more importantly, digital is changing one's view of the self - especially in communication and digital human interactions. The "selfie," a new digital behaviour, makes the smartphone an extension and projection of one's self. 
Digital communication and tools have already moved many from industrial models of work and have changed expectations of work-related roles. Management of digital information is a growing field, but management of people is rapidly shrinking - the digital voice is individual and seeks to be creative and productive in new ways, so management increasingly involves managing technology.

\subsection{Digitalism is a framework of thinking about the world and interacting in it}

Digital life and real life seem to be moving in parallel and concurrent flows of behaviour, sometimes related, sometimes not.

Digitalism is changing how artists create and communicate their art and their artistic persona. Through various digital modes, artists can engage the viewer/participant, can network their art, and speak to its meaning. Thus, the artist can take an active role in creating a digital identity. Digitalism challenges the notion of what constitutes the original artwork, raising issues of how and if it will be preserved.

Digitalism has transformed writing, reading, and publishing. Textual information is no longer privileged as information flows across all media and is tied to communication across global networks.

\subsection{Digital Information Behaviour}

Digital Speak (T. Giannini, 2014)
Looking at you
You text me
My cell sounds
An email found
Click -
I hear your digital voice
On YouTube
Your digital self speaks
Your analogue voice
I can't remember
Holding my cell
I can't let go
What's next
I don't know
Digital suspense
Losing my sense
of reality

The relationship of people to information is digital, from born-digital documents and digital capture to digital tools for creating information and communicating it. This shift has transformed information processing: e.g., for online scholarly articles/documents (Giannini 2003) and for libraries, archives, and museums, through digitisation of archival collections finding global audiences who can tweet and blog about them, potentially communicating new information (Giannini \& Bowen 2014).

Users visit cultural institutions with their digital tools (smartphone, tablet, computer, etc.). They capture and curate information as "digital take-away", to be used to create new works or to share in cyberspace. These users come to these cultural institutions with their digital information behaviour in tow and with the expectation of using the same behaviours inside and outside as if they flowed seamlessly being part of the same digital system. Digital information behaviour is participatory and interactive as opposed to the hierarchical models of traditional library interactions, so that the roles of information professionals and users resonate in an interdependent system tied to digital information sharing, showing, seeing, saying, telling, capturing, curating, and connecting. In essence, digital information behaviour cannot be separated from the broader sphere of digital behaviour viewed from the perspective of digitalism (Giannini 1999b).

Digitalism theorises a unifying principle that digital can be applied to all things. This is reflected across disciplinary research, for example, digital science, digital humanities, digital art and design, digital information, digital society and digital culture, digital communication, and digital philosophy. Each digital instance is studied in its own terms, whereas digitalism considers the unifying principles of these phenomena.

\section{CONCLUSION}

"The digital revolution is far more significant than the invention of writing or even of printing."

- Douglas Engelbart (1925-2013)

inventor of the mouse

Digitalism, in the context of this paper with respect to different disciplinary fields, in the framework of IT and sociology, is the creeping ubiquity of a digitally enhanced lifestyle by people in societies with access to advanced technology. The digital experience combines with reality to become an integral part of a person's life. This occurs especially when the technology has been in existence for the entire memory of a person and this is now the case of a significant number of younger people in the world. Access to digital information and communication by digital means is so universal that those with the technology do not contemplate living without it. Digitalisation is now intrinsic to arts and culture as well as to the human desire to share activities and experiences with friends, even if they are not physically present at the time. This is now so easy to do that it is done as a matter of course by many without a second thought or even consciousness of it.

Some fields have been almost completely transformed, such as photography (Diprose \& Robins 2012). Other aspects are in a state of potentially radical change with new challenges, such as copyright issues (Numerico \& Bowen 2006).

Digitalism proceeds at different rates for various activities of our lives. Books and reading are partially digital; photography and video are essentially entirely digital now. Telephone boxes 
are largely redundant due to mobile phones. However, small-scale payments are still largely through physical cash, as witnessed by the conversion of telephone boxes to cash machines (see Figure 8:).

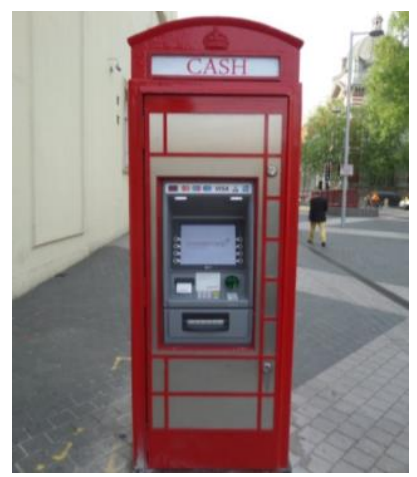

Figure 8: A redundant telephone box becomes a cash machine in Exhibition Road, London (outside the Victoria and Albert Museum)

This paper has attempted to provide a sketch of digitalism and to capture the current state of its development, especially with respect to the arts and information. Of course there are many more aspects to consider and much has been outlined in overview or omitted here, for example games (Angelides \& Agius 2014), fiction (Brown 2004), etc. It will be interesting to see where digitalism leads in the next decade, with its combination of digitality and reality.

\section{REFERENCES}

Anderson, J., and Rainie, L. (2014) Digital Life in 2025. Pew Research Internet Project. http://www.pewinternet.org/2014/03/11/digital-lifein-2025/ (accessed 25 May 2014).

Angelides, M. C., and Agius, H. (eds.) (2014) Handbook of Digital Games. Wiley-IEEE Press.

Baker, N. (2002) Double Fold: Libraries and the Assault on Paper. Vintage.

Bakshee, I. (1999) The Pattern of Beauty: The Art of Igor Bakshee. Wolfram Media, Graphica 2: The World of Mathematica Graphics.

Beazley, I., Bowen, J.P., McDaid, S., and Liu, A.H.Y. (2010) Dulwich OnView: An art museum-based virtual community generated by the local community,. In A. Seal, J.P. Bowen, and K. Ng (eds.), EVA London 2010 Conference Proceedings. British Computer Society, Electronic Workshops in Computing, pp. 79-86.

http://ewic.bcs.org/content/ConWebDoc/36053

(accessed 26 May 2014).

Berners-Lee, T. (1999) Weaving the Web. Orion Business Books.

Black, S., Bowen, J. P., and Griffin, K. (2010) Can Twitter save Bletchley Park? In D. Bearman and J. Trant (eds.), MW2010: Museums and the Web 2010, Denver, USA, 9-12 April. Archives \&
Museum Informatics, 2010.

http://www.archimuse.com/mw2010/papers/black/bl ack.html (accessed 25 May 2014).

Bowen, J. P. (2012) Alan Turing. In A. Robinson (ed.), The Scientists: An Epic of Discovery. Thames \& Hudson, pp. 270-275, 2012.

Bowen, J. P. (2013) Online communities: visualization and formalization. In Cyberpatterns 2013: Proc. Second International Workshop on Cyberpatterns - Unifying Design Patterns with Security, Attack and Forensic Patterns, Abingdon, UK, 8-9 July. Oxford Brookes University.

Bowen, J. P. and d'Inverno, M. (2006) Confessions of computer scientists working in the arts: a tale of two techies. In J. Hemsley, S. Keene, L. MacDonald, J.P. Bowen, V. Cappellini, and G. Stanke (eds.), EVA 2006 London Conference Proceedings, London, UK, 26-28 July 2006. EVA Conferences International, pp. 15.1-15.10.

Bowen, J. P., Keene, S., and Ng, K. (eds.), (2013) Electronic Visualisation in Arts and Culture. Springer, Series on Cultural Computing.

Brown, D. (2004) Digital Fortress. Corgi Books.

Brown, P., Gere, C., Lambert, N. and Mason, C. (eds.) (2008) White Heat Cold Logic: British Computer Art 1960-1980. The MIT Press.

Darius, J. (1984) Beyond Vision. Oxford University Press.

Daudier, Y.-S. (2001) The Emergence of Digitalism: The Significant Development of Digital Paintings in Computer Art, C. 1990-2000. Fashion Institute of Technology. Program in Gallery and Retail Art Administration.

Diprose, G., and Robins, J. (2012) Digital Photography: A New Introduction. Thames \& Hudson.

Edmonds, E., and Franco, F. (2013) From communications game to Cities Tango, International Journal of Creative Computing, 1(1), pp. 120-132.

Evans, C. (1979) The Mighty Micro. Victor Gollancz.

Fox, S., and Rainie, L. (2014) The Web at 25 in the U.S. Pew Research Internet Project.

http://www.pewinternet.org/2014/02/27/summaryof-findings-3/ (accessed 25 May 2014).

Gayford, M. (2011) A Bigger Message: Conversations with David Hockney. Thames \& Hudson.

Filippini-Fantoni, S., and Bowen, J. P. (2008) Mobile multimedia: Reflections from ten years of practice. In L. Tallon and K. Walker (eds.) Digital Technologies and the Museum Experience. AltaMira, pp. 79-96. 
Giannini, T. (1999a) Information Receiving, a Primary Mode of the Information Process. In Proceedings of the 61st Annual Meeting of the American Society for Information Science Information Access in the Global Information Economy. Information Today, pp. 362-371.

Giannini, T. (1999b) Modeling the reference process online. In Proceedings of the Twentieth National Online Meeting, Information Today, pp.133-143.

Giannini, T. (2003) The music library of JeanBaptiste-Christophe Ballard, sole music printer to the king of France, 1750 inventory of his grand collection brought to light. In Repertoire Internationales des Sources Musicale (RILM). http://mysite.pratt.edu/ giannini/ballard.htm

(accessed 25 May 2014).

Giannini, T. and Bowen, J. P. (2014) The Brooklyn Visual Heritage website: Brooklyn's museums and libraries collaborate for Project CHART. In MW2014: Museums and the Web 2014, Baltimore, USA, 2-5 April.

http://mw2014.museumsandtheweb.com/paper/thebrooklyn-visual-heritage-website/ (accessed 20 May 2014).

Greene, R. (2004) Internet Art. Thames \& Hudson, World of Art.

Harrison, K., Bowen, J. P., and Bowen, A. M. (2013) Electronic visualisation in chemistry: from alchemy to art. In $\mathrm{K}$. $\mathrm{Ng}$, J.P. Bowen, and $\mathrm{S}$. McDaid (eds.), EVA London 2013: Electronic Visualisation and the Arts. British Computer Society, Electronic Workshops in Computing, pp. 267-274. http://ewic.bcs.org/category/17656 (accessed 20 May 2014).

Hoy, M. A. (2010) From Point to Pixel: A Genealogy of Digital Aesthetics. Electronic Theses and Dissertations, University of California Berkeley, USA. http://escholarship.org/uc/item/25f4v730 (accessed 25 May 2014).

Hugill, A. and Yang, H. (2013) The creative turn: New challenges for computing, International Journal of Creative Computing, 1(1), pp. 4-19.

Ishimaru, T. and Yokogawa, H. (2006) Olfactory and gustatory disturbances caused by digitalism: A case report. Auris Nasus Larynx, 33(4), pp. 465469. doi: 10.1016/j.anl.2006.03.004

Lawrence, G., and Stump, M. (2012) Connecting physical and digital worlds: a case study of quick response codes and social media in a gallery setting, The International Journal of Design in Society, 6(3), pp. 79-95.

Liu, A. H-Y., and Bowen, J. P. (2011) Creating online collaborative environments for museums: A case study of a museum wiki, International Journal of Web Based Communities, 7(4), pp. 407-428.
McLuhan, M. (1962) The Gutenberg Galaxy: The Making of Typographic Man. University of Toronto Press.

McLuhan, M. (1992) The Global Village: Transformations in World Life and Media in the 21st Century. Oxford University Press.

Muenz, H. (2010) Live random concepts and sightreading players: The role of the computer in the era of digested digitalism. Contemporary Music Review, 29(1), pp. 81-87. doi:10.1080/07494467.2010.509597

Negroponte, N. (1995) Being Digital. Hodder \& Stoughton.

Numerico, T., and Bowen, J. P. (2006) Copyright protection and cultural heritage: Steering digitization between public archives and search engines. In J. Hemsley, S. Keene, L. MacDonald, J. P. Bowen, V. Cappellini, and G. Stanke (eds.), EVA 2006 London Conference Proceedings, London, UK, 26-28 July. EVA Conferences International, pp. 6.1-6.7.

Perry, G. (2013) The Vanity of Small Differences. Hayward Publishing.

Robinson, A. (2010) Creative science versus artistic creation. In Sudden Genius? Oxford University Press, Chapter 18, pp. 279-291.

Quinion, M. (2002) Ologies and Isms. Oxford University Press, p. 58.

Standage, T. (1999) The Victorian Internet. Berkley Books.

Sula, C. A. (2013) Qualifying culture: four types of value in visualisation, Chapter 3 , pp. 25-37. In Bowen et al. (2013).

Trott, M. (1999) The Imaginary Made Real: The Art of Michael Trott. Wolfram Media, Graphica 1: The World of Mathematica Graphics.

University of Cambridge Museums (2014) Discoveries: Art, Science \& Exploration, Two Temple Place, London, pp. 16-17.

van Doren, C. (1991) A History of Knowledge: Past, Present, and Future. Ballantine Books.

Weisberg, R. W. (2006) Creativity: Understanding Innovation in Problem Solving, Science, Invention, and the Arts. Wiley.

Wiedemann, J. (2001) Digital Beauties. Taschen.

Wieners, B., and Pescovitz, D. (1996) Reality Check. HardWired.

Wikipedia (2014) Digital philosophy. https://en.wikipedia.org/wiki/Digital philosophy (accessed 20 May 2014).

Wolfram, S. (2002) A New Kind of Science. Wolfram Media. 